\title{
The global impact of supersaturation in a coupled chemistry-climate model
}

\author{
A. Gettelman and D. E. Kinnison \\ National Center for Atmospheric Research, Boulder, CO, USA \\ Received: 3 November 2006 - Published in Atmos. Chem. Phys. Discuss.: 1 December 2006 \\ Revised: 8 February 2007 - Accepted: 16 March 2007 - Published: 27 March 2007
}

\begin{abstract}
Ice supersaturation is important for understanding condensation in the upper troposphere. Many general circulation models however do not permit supersaturation. In this study, a coupled chemistry climate model, the Whole Atmosphere Community Climate Model (WACCM), is modified to include supersaturation for the ice phase. Rather than a study of a detailed parameterization of supersaturation, the study is intended as a sensitivity experiment, to understand the potential impact of supersaturation, and of expected changes to stratospheric water vapor, on climate and chemistry. High clouds decrease and water vapor in the stratosphere increases at a similar rate to the prescribed supersaturation (20\% supersaturation increases water vapor by nearly $20 \%$ ). The stratospheric Brewer-Dobson circulation slows at high southern latitudes, consistent with slight changes in temperature likely induced by changes to cloud radiative forcing. The cloud changes also cause an increase in the seasonal cycle of near tropopause temperatures, increasing them in boreal summer over boreal winter. There are also impacts on chemistry, with small increases in ozone in the tropical lower stratosphere driven by enhanced production. The radiative impact of changing water vapor is dominated by the reduction in cloud forcing associated with fewer clouds $\left(\sim+0.6 \mathrm{Wm}^{-2}\right)$ with a small component likely from the radiative effect (greenhouse trapping) of the extra water vapor $\left(\sim+0.2 \mathrm{Wm}^{-2}\right)$, consistent with previous work. Representing supersaturation is thus important, and changes to supersaturation resulting from changes in aerosol loading for example, might have a modest impact on global radiative forcing, mostly through changes to clouds. There is no evidence of a strong impact of water vapor on tropical tropopause temperatures.
\end{abstract}

Correspondence to: A. Gettelman

(andrew@ucar.edu)

\section{Introduction}

Condensation in the atmosphere occurs when the partial pressure of water vapor is higher than the saturation vapor pressure over liquid or ice (Murphy and Koop, 2005). While this statement is basically correct for liquid, where supersaturations of more than a fraction of a percent rarely persist, it is not true for ice processes (Kärcher and Haag, 2004). Significant supersaturations over ice are seen routinely in the atmosphere from aircraft (Jensen et al., 2005), balloons and radiosondes (Spichtinger et al., 2003a) and satellites (Jensen et al., 1999; Spichtinger et al., 2003b; Gettelman et al., 2006) This is not surprising when one considers the condensation and freezing process for molecules of $\mathrm{H}_{2} \mathrm{O}$ in the atmosphere. Condensation of vapor to ice is essentially a 2 step process, requiring condensation to liquid and then freezing (Koop et al., 2000). Since the saturation vapor pressure over water is higher than that over ice at low temperatures, in clear air we expect to see ice supersaturation before condensation occurs.

Supersaturation may have significant impacts on the state of the atmosphere. Making the most simple assumptions, if one allows $20 \%$ more water to be present before condensation, and stratospheric water vapor is limited by temperature dependent condensation at the tropical tropopause (Holton and Gettelman, 2001), we might expect a corresponding increase of $20 \%$ in upper tropospheric and stratospheric water vapor, and a drop in high cloud cover. Changes to the condensation threshold would be due to differences in water activity (Koop et al., 2000).

Such changes would have significant impacts on climate and chemistry. Changes in high cloud cover would have significant effects on tropospheric climate and the radiation balance of the atmosphere. A reduction in high clouds may substantially increase outgoing longwave radiation at the top of the atmosphere. Since high clouds generally heat, this would lead to a cooling effect on the climate system. Alternatively, since the overall effect of clouds is to cool (Cess,

Published by Copernicus GmbH on behalf of the European Geosciences Union. 
2005) by reflecting radiation to space, a reduction in clouds might warm the planet, though it is mostly thick, low clouds that have a net cooling effect.

Changes in stratospheric water may have effects on both chemistry and climate. Since water is the dominant species in the stratospheric hydrogen budget, we might also expect differences in hydrogen radicals $\left(\mathrm{HO}_{\mathrm{x}}=\mathrm{OH}+\mathrm{HO}_{2}\right)$ in the stratosphere, leading to changes in ozone and other trace species chemistry, particularly where hydrogen radicals dominate ozone chemistry in the lower stratosphere (Wennberg et al., 1994). In addition, stratospheric water vapor changes have been shown to impact tropospheric temperatures (Forster and Shine, 2002). Recently Stuber et al. (2001) and others (Stuber et al., 2005; Joshi et al., 2003; Shindell, 2001) have speculated about a "stratospheric water vapor feedback" whereby changes in greenhouse gases force increases in tropopause temperatures, and these temperature changes induce increases in stratospheric water which may further increase tropospheric temperatures.

Most global models, however, use large-scale closure schemes for condensation that include assumptions that do not permit supersaturation with respect to liquid or ice (for example, Rasch and Kristjansson, 1998). For very large (100s of $\mathrm{km}$ ) regions represented by global model grid cells this was thought to be a reasonable assumption. However, recent work with aircraft data (Gierens and Spichtinger, 2000) on long flight tracks and with satellites (Gettelman et al., 2006) has shown that even at these scales supersaturation may be present.

To better understand potential aerosol indirect effects on climate, more detailed treatments of ice cloud nucleation and microphysics are being developed for global models. Including representations of supersaturation will be critical for appropriately nucleating ice clouds (Kärcher et al., 2006) and for representing the affects of aerosol nucleation and freezing for ice clouds (Kärcher and Lohmann, 2002a,b).

Thus representation of supersaturation in global models may be important for understanding both stratospheric chemistry and tropospheric climate. This work will perform a sensitivity experiment to test this hypothesis. In this work we present simple modifications to a coupled chemistry climate model which permit bulk supersaturation with respect to ice, and use the model to understand the impact of supersaturation on simulated climate and chemistry of the upper troposphere and lower stratosphere (UT/LS) region. We emphasize that this work is not an attempt to realistically model supersaturation. It is a simple and crude method within the context of a coupled chemistry climate model to examine the impact of supersaturation and increased stratospheric water vapor. This then allows us in a consistent way to understand feedbacks on stratospheric chemistry and atmospheric dynamics.

The model and methodology is described in Sect. 2, the results are presented in Sect. 3 and conclusions are contained in Sect. 4.

\section{Methodology}

The principle behind this work is to take a state of the art coupled chemistry climate model, and allow grid box averaged supersaturation in the simulations. Below we describe the model, the simple changes we have made, and the simulations we have performed. The purpose is not so much to evaluate the performance of the simulations against observations but to examine the differences as a result of supersaturation.

\subsection{Model description}

For this work we have utilized the Whole Atmosphere Community Climate Model, Version 3 (WACCM3) developed at the National Center for Atmospheric Research (NCAR). WACCM3 is a state of the art coupled chemistry climate model that spans the atmosphere from the surface to the lower thermosphere $(\sim 140 \mathrm{~km})$. The model is described by Garcia et al. (2007) ${ }^{1}$, and performs well relative to observations and to other coupled models (Eyring et al., 2006). Horizontal resolution is $4^{\circ} \times 5^{\circ}$. Vertical resolution is about $1 \mathrm{~km}$ in the UT/LS region. We note some of the relevant features for this study below.

WACCM3 is based on the framework of the Community Atmosphere Model, version 3 (CAM3), a General Circulation Model (GCM), described by Collins et al. (2006). WACCM3 uses CAM3 as its base, and adds parameterizations for chemistry and upper atmospheric processes. The CAM model top is typically $2 \mathrm{hPa}(45 \mathrm{~km})$, while the WACCM model top is $5 \times 10^{-6} \mathrm{hPa}(140 \mathrm{~km})$. The chemistry module for WACCM3 is derived from the three dimensional chemical transport Model for Ozone and Related chemical Tracers (MOZART) (Brasseur et al., 1998; Horowitz et al., 2003; Kinnison et al., $2007^{2}$ ). The chemistry package comprises 56-species and represents chemical and physical processes in the middle atmosphere, including inorganic nitrogen, hydrogen, chlorine and bromine chemistry, along with $\mathrm{CH} 4$ and its degradation products. Heterogeneous processes on sulfate aerosols and polar stratospheric clouds are included. Surface fluxes of chemical species as well as NOx $\left(\mathrm{NO}+\mathrm{NO}_{2}\right)$ and $\mathrm{CO}$ sources from lightning and aircraft emissions are included, as are wet and dry deposition. The chemistry is coupled in-line to the model dynamics and radiation, so that chemical species (such as ozone) affect model heating rates.

WACCM3 uses CAM3 routines for condensation and the hydrologic cycle. The model has a bulk microphysics scheme with prognostic vapor, liquid and ice that are

\footnotetext{
${ }^{1}$ Garcia, R. R., Marsh, D., Kinnison, D., Boville, B. A., and Sassi, F.: Simulations of secular trends in the middle atmosphere, 1950-2003, J. Geophys. Res., submitted, 2007.

${ }^{2}$ Kinnison, D. E., Brasseur, G. P., Walters, S., et al.: Sensitivity of Chemical Tracers to Meteorological Parameters in the MOZART3 Chemical Transport Model, J. Geophys. Res., in review, 2007.
} 
conserved and advected (Rasch and Kristjansson, 1998). Fractional cloudiness is the trigger for condensation and it is constrained by relative humidity $(\mathrm{RH})$ following Slingo (1987), such that condensation begins at $90 \%$ relative humidity. No supersauration is permitted, and excess vapor is converted to condensate. The microphysics reduces to rate processes for determining how much condensate will precipitate at each timestep, and the humidity is constrained by the cloud fraction and condensation (macrophysics) scheme.

CAM uses a "combined" relative humidity that reflects relative humidity with respect to water for temperatures above $-10^{\circ} \mathrm{C}$, with respect to ice below $-30^{\circ} \mathrm{C}$, and a linear combination of the saturation vapor pressure between these limits. The simulation of the hydrologic cycle is described by Boville et al. (2006).

\subsection{Supersaturation}

Because the bulk microphysics formulation of Rasch and Kristjansson (1998) used in WACCM3 does not permit supersaturation with respect to ice, we have modified the formulation of the Slingo (1987) cloud fraction scheme so that the critical relative humidity threshold for starting to form cloud increases when ice is present, and can be higher than $100 \%$ RH. In the standard WACCM3 case, cloud begins to form at a relative humidity of $90 \%$, and $100 \%$ cloud cover occurs at $100 \%$ RH. This has been modified for ice clouds so that for pure ice conditions (temperatures below $-30^{\circ} \mathrm{C}$ ), cloud does not begin to form until $\mathrm{RH}=110 \%$ and full $(100 \%)$ cloud cover occurs at $\mathrm{RH}=120 \%$. These values are the model "merged" relative humidity. As noted above, this means that for temperatures below $-30^{\circ} \mathrm{C}$, condensation will not fully occur until $\mathrm{RH}=120 \%$ over ice. Once clouds are present, the model relaxes humidity back towards ice saturation $(\mathrm{RH}=100 \%)$.Evaporation only occurs when $\mathrm{RH}$ is below $100 \%$.

We note that our motivation with this scheme is to simulate the effects of supersaturation (more stratospheric water vapor and fewer ice clouds) in a manner consistent with the model physics. We are not trying to model the ice nucleation process or to physically represent supersaturation or the observed distribution of supersaturation (see below). The value of $120 \%$ is chosen as being representative of threshold values for heterogenous nucleation of ice crystals (Kärcher and Lohmann, 2002a), and a RH value which is observed with $0.01 \%$ frequency (see Fig. 1).

This is of course not the ideal or preferable way to represent supersaturation in a model. Other approaches, such as the treatment of Kärcher and Lohmann (2002a), allow proper representation of condensation of ice through homogeneous and/or heterogeneous nucleation and freezing of cloud particles on to aerosols. However, the bulk representation described above is internally consistent with the WACCM3 hydrologic cycle, and we hypothesize that this will increase the amount of water vapor and decrease condensation and clouds in the simulation in a geophysically realistic way, without fixing or adding water vapor to the model. Other simulations which have attempted to investigate the effect of increases in stratospheric water vapor have generally fixed water or explicitly enhanced its concentration (e.g. Forster and Shine, 2002; Stuber et al., 2005; Stenke and Grewe, 2005). This sensitivity study should be thought of as imposing supersaturation, which is conceptually between imposing water vapor changes and explicitly modeling microphysical processes that give rise to supersaturation, but allows us to consistently examine the effect of imposed supersaturation.

\subsection{Impact}

The results of the supersaturation treatment described above are illustrated in Fig. 1 and compared to observations in the upper troposphere over $\pm 45^{\circ}$ latitude. The figure represents instantaneous output every 15 days during one year of simulation and daily observations from the year 2004. Note that the vertical scale is expanded using logarithmic scaling. The base case simulation (solid gray line) has a maximum permitted relative humidity of $100 \%$, and an increase in the frequency of RH values just below this. This is not observed in RH measurements from the Atmospheric Infrared Sounder (AIRS-black solid line). AIRS measurements of RH and the frequency of supersaturation in AIRS are discussed by Gettelman et al. (2006). Figure 1 uses an updated version (version 4) of the AIRS retrieval which has less supersaturation than reported by Gettelman et al. (2006).

The changes to the cloud scheme in the model discussed above result in a shift of the PDF into the supersaturated range for the supersaturated (SSAT) case. The extent and frequency of supersaturation in the simulations is now larger than observed, with the simulation over predicting supersaturation between 100-150\% RH and under-predicting it at higher values. Additional constraints could be added to the scheme to better reproduce the RH PDF in Fig. 1, but our goal is merely to generate some modest supersaturation. As noted, better treatments designed to represent the nucleation process would produce better results. These simulations are intended as a self consistent sensitivity study.

\subsection{Simulations}

For analysis, two 22 year integrations of WACCM3 were performed at $4^{\circ} \times 5^{\circ}$ horizontal resolution. The model has 66 levels in the vertical with resolution of about $1 \mathrm{~km}$ in the UT/LS region. In one (Base) simulation the standard WACCM3 configuration was used with annually repeating 1995 boundary conditions. This includes Sea Surface Temperatures from 1995 and levels of $\mathrm{CO}_{2}$ and chlorine compounds appropriate for that year. An identical "supersaturated" (SSAT) simulation was run with the same boundary conditions, but with the code modified to allow supersaturation for the ice phase as described above. The last 15 years of 


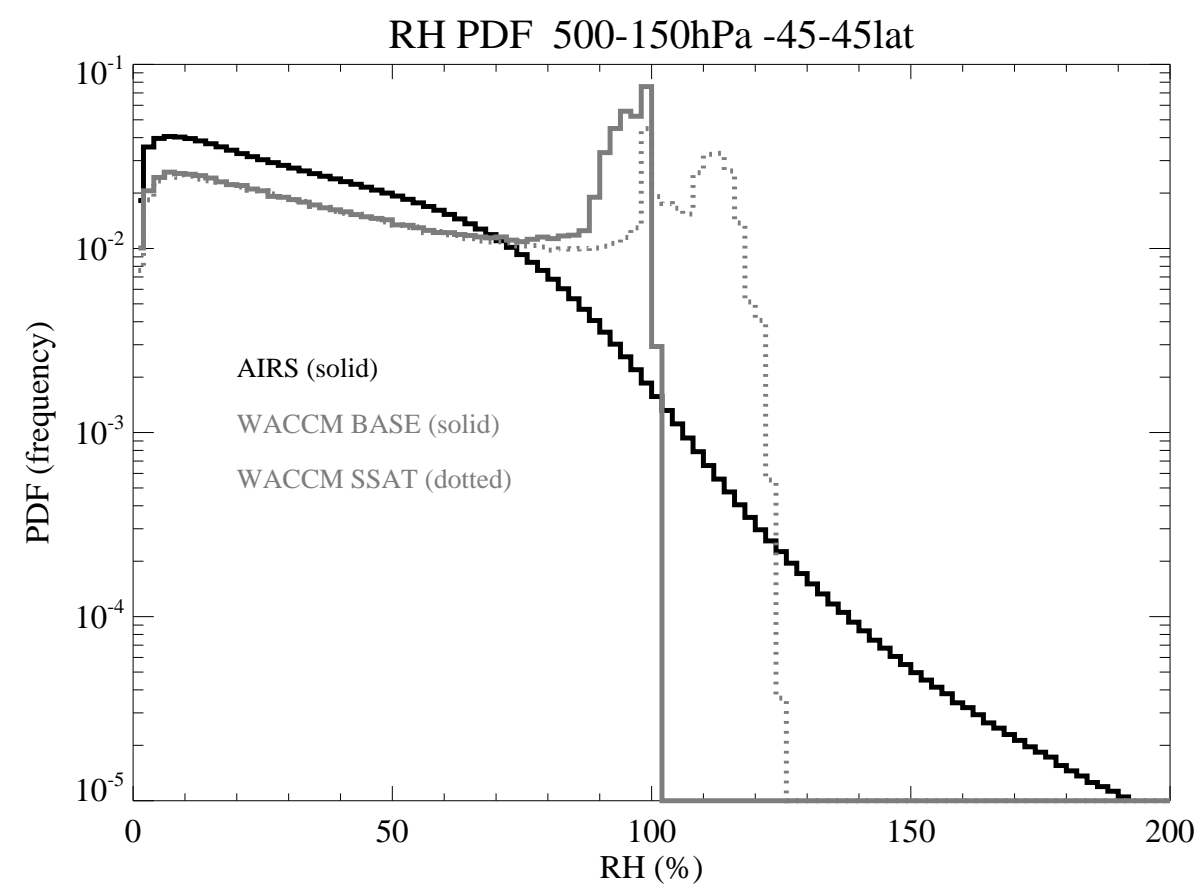

Fig. 1. Probability Distribution Functions (PDFs) over $500-150 \mathrm{hPa}$ and $\pm 45^{\circ}$ latitude for AIRS RH observations for 2004 (black), the base WACCM simulation (solid gray) and supersaturated WACCM simulation (dotted gray).

model output is used for all analysis. We have repeated the analysis in this paper on varying sets of 5 and 10 year periods from each run. All the conclusions are qualitatively robust relative to inter-annual variations. There are some quantitative differences in the extra-tropics where variability is larger, but the conclusions are unchanged.

\section{Results}

In this section we discuss the main results from comparing the two WACCM3 simulations, referred to as the "Base" and "SSAT" (or "supersaturated") cases. We will first discuss cloud and water vapor fields since these are most directly impacted by the changes. We will then discuss the impact on the circulation (transport) and temperature, including chemical tracers of transport. We will then discuss ozone and other chemical species, and finally examine the radiative balance of the simulations and how they are related to other differences.

\subsection{Clouds}

In the tropics, the maximum zonal mean cloud fraction for high clouds in the base simulation is found at $200-250 \mathrm{hPa}$ (0.4). At the tropopause, cloud fraction is 0.2. The latter is almost exclusively cirrus clouds generated from the stratiform cloud parameterization. By raising the threshold for high (ice) cloud formation, the mean cloud fraction is de- creased by nearly half (cloud fraction goes down by 0.17 from 0.4), as indicated in Fig. 2a. At pressures greater than $600 \mathrm{hPa}$ the differences are minor. The largest decreases are at $200 \mathrm{hPa}$ and coincident with the maximum high level cloudiness. There are smaller changes at high latitudes. Analysis of cloud changes sorted by optical depth indicates that most of the changes are to high clouds with optical depth less than 3.6, which are defined as cirrus clouds based on the International Satellite Cloud Climatology Project (ISCCP). The largest changes are to clouds with optical depths less than 0.3 (thin cirrus). Regionally the largest changes occur where the cloud fractions are largest, in the tropical Western Pacific region. Changes are larger in June-August than in December-February.

Consistent with the change in cloudiness, model grid box averaged cloud ice mixing ratio goes down almost everywhere in the simulations with supersaturation (Fig. 2b). As a result of the scheme which permits in-cloud supersaturation, in-cloud ice water paths also decrease. In the tropical upper troposphere, the change is up to $-50 \%$ and maximizes near the freezing level. Cloud liquid is less affected. As a result total precipitable water decreases by only $10 \%$ in tropics (not shown), because ice is only $15 \%$ of total condensate.

Associated with this decrease in cloudiness is a small increase in global mean precipitation. The global increase in both rate and total is about $4 \%$, and occurs mostly in the central to eastern Pacific Inter-Tropical Convergence Zone (ITCZ), and over the Atlantic ocean. There are slight 

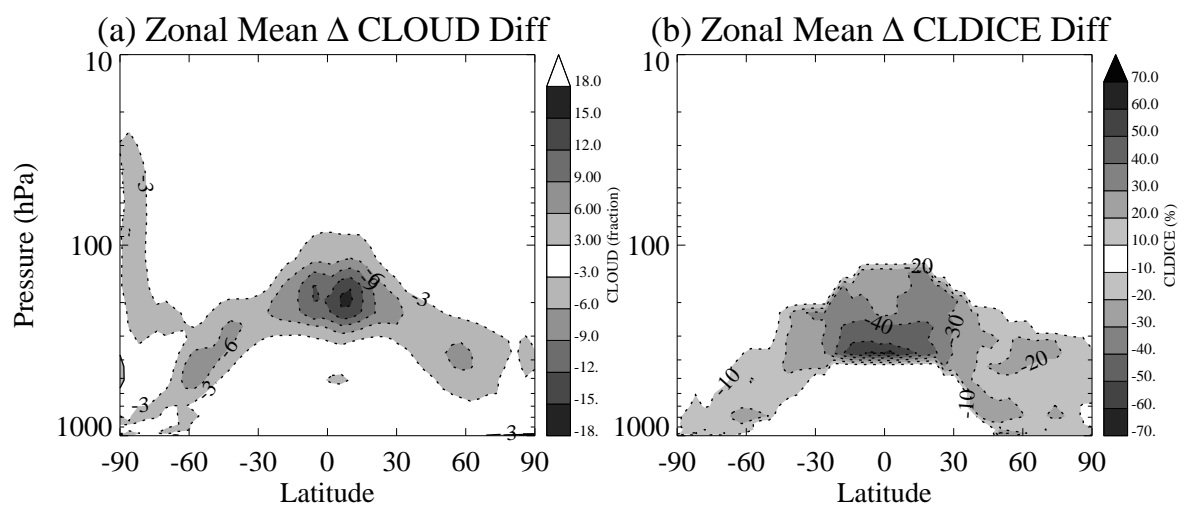

Fig. 2. Annual zonal mean percent differences (Supersaturation - Base)/Base in (A) cloud fraction and (B) cloud ice water mixing ratio.

decreases in precipitation over the Indian Ocean. This decrease is consistent with a $5 \%$ decrease in total precipitable water, a consequence of the reduction in lower tropospheric water vapor (see below), and does not represent a significant change to the hydrologic cycle or to the lifetime of humidity in the atmosphere. The base simulation generally has too much precipitation in the central to eastern Pacific and the Indian ocean.

The radiative impact of clouds is usually assessed by examining the cloud forcing, which is the difference of the top of atmosphere radiation and the radiation assuming a clear sky (e.g. Ramanathan et al., 1989). Short and longwave cloud forcing are calculated from the model using this method. With supersaturation and a reduction in cloudiness, the magnitudes of both shortwave and longwave forcing drop. The global average longwave cloud forcing is $30 \mathrm{Wm}^{-2}$ in the base case, and drops by $7 \mathrm{Wm}^{-2}$. The shortwave cloud forcing is $-53 \mathrm{Wm}^{-2}$ (clouds cool in the shortwave), and drops by $-8 \mathrm{Wm}^{-2}$ (to $-45 \mathrm{Wm}^{-2}$ ) The net cloud forcing in the model is $-22 \mathrm{Wm}^{-2}$ and changes by $+0.6 \mathrm{Wm}^{-2}$. The one standard deviation $(\sigma)$ interannual variability of total net cloud forcing in either simulation is $\sim 0.15 \mathrm{Wm}^{-2}$, so we estimate the $2 \sigma$ uncertainty ( $95 \%$ confidence interval) as $+0.6 \pm 0.3 \mathrm{Wm}^{-2}$.

We expect reductions in longwave forcing with the reduction in cirrus clouds, but the magnitude of the reductions is large enough to strongly reduce shortwave cloud forcing as well (and slightly more than the total longwave forcing), particularly over the Indian Ocean. The cloud forcing changes appear largely due to changes in simulated cirrus clouds. Changes in clouds are slightly larger during June-August than during December-February. As noted, these 15 year runs are sufficient to get global mean statistics on total cloud forcing within a few tenths of a watt $\left(0.3 \mathrm{Wm}^{-2}\right)$ so these are significant, at least globally. Regional or seasonal changes in cloud forcing may not be significant.

\subsection{Water vapor}

Like the changes in cloudiness, the changes in water vapor are expected from the changes to the physics in the simulation. In general, with the reduction in condensation, specific humidity and relative humidity $(\mathrm{RH})$ increase in the upper troposphere throughout the stratosphere. This is illustrated in Fig. 3. Where RH is highest in the tropical UT/LS region and at high polar latitudes, RH increases by up to $12-15 \%$ (Fig. 3a). There are slight decreases in humidity at lower altitudes, below $300 \mathrm{hPa}$ in the tropical middle troposphere, which is very close to the average freezing level in the simulations. This is perhaps due to raising of the condensation level. Water vapor (specific humidity) increases as well in the regions where the large scale cloudiness scheme controls its value: mostly in the tropical tropopause layer (Fig. 3b). Water vapor increases of up to $20 \%$ are seen just above the tropical tropopause, with values increasing everywhere in the stratosphere, but by lower percentage amounts as air is further from the tropical tropopause and RH is only a few percent.

Understanding the seasonality of these changes is critical for understanding their cause. Water vapor values in the tropical lower stratosphere have a strong seasonal cycle (Mote et al., 1996) with a minimum in boreal winter and a maximum in boreal summer. This signal propagates vertically from the tropical tropopause as the air ascends due to the Brewer-Dobson circulation (Holton et al., 1995). The simulated "tropical tape recorder" signal (Mote et al., 1996) in water vapor from the base run is illustrated in the top panel of Fig. 4. Figure 4 shows a composite repeated annual cycle based on monthly means of the base simulation.

In general the annual cycle in the base WACCM3 simulation (top panel of Fig. 4) compares quite well to observations of water vapor in the stratosphere (Randel et al., 2001; SPARC, 2000). The minimum in water vapor occurs $1-2$ months later in the simulation than in observations, but the speed of propagation and attenuation is appropriate. Mixing 

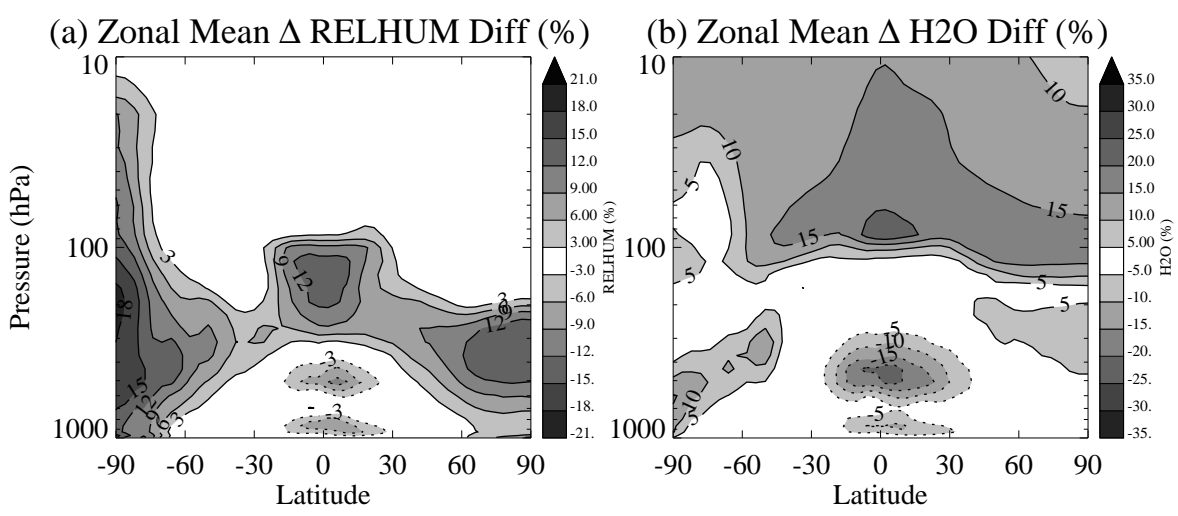

Fig. 3. Annual zonal mean differences (Supersaturation - Base) in (A) Relative Humidity and (B) water vapor (specific humidity) mixing ratio.

ratios in the base case are generally 0.5 ppmv dry relative to observations, slightly more dry in boreal summer. For a full discussion of WACCM3 performance in this regard, see Garcia et al. (2007) ${ }^{1}$.

The lower panel of Fig. 4 illustrates the differences between the model with supersaturation and the base case. Consistent with Fig. 3, water vapor increases almost everywhere, except in the troposphere below $100 \mathrm{hPa}$ from January-March.

The increases are largest in boreal summer and fall from September-November. This is the period when cooling of the tropical tropopause region is strongly affecting water vapor. Note that the differences between the simulations occur in the lower stratosphere and also propagate vertically. Overall there is nearly 1 part per million by volume (ppmv) more water vapor in the stratosphere in the supersaturation case. Overall the changes improve the simulation of water vapor in the stratosphere. In order to determine the cause of these changes, it is instructive to examine changes in temperature as well.

\subsection{Temperature}

Figure 5 illustrates the annual zonal mean change in temperature between the simulations. There are slight and coherent changes in temperature in the simulations with supersaturation. In general there are decreases of annual mean temperature in the upper tropical troposphere by $0.5-1{ }^{\circ} \mathrm{K}$. These changes may be due to several factors. First, the increase in water vapor in the upper troposphere will increase clear sky cooling. Second, the decrease in cloud fraction decreases any heating due to local absorption by clouds and increases the effect of the clear sky cooling. Changes to dynamics may also play a role (see below). The region of cooling in the tropical upper troposphere $(400-100 \mathrm{hPa})$ in Fig. 5 is similar to the region of reduced cloudiness in Fig. 2a. In the lower stratosphere there is an increase in temperature of up to $1.5^{\circ} \mathrm{K}$. This is consistent with decreased clouds below this region leading to more longwave absorption in the lower stratosphere. It may also indicate changes in the strength of the stratospheric wave-driven Brewer-Dobson circulation, which will be discussed in more detail below. Consistent with a change in the global circulation, there are colder temperatures in the southern polar stratosphere. At $85 \mathrm{hPa}$, the spatial pattern of tropical temperature changes has increases nearly everywhere along the equator, with maximum changes over the equatorial eastern Pacific, and the equatorial western Pacific. In the upper stratosphere and mesosphere, there is cooling of up to $1.5 \mathrm{~K}$ (not shown), consistent with increased water vapor throughout the stratosphere below.

The temperature changes are not symmetric throughout the year. Figure 6 is similar to Fig. 4 but illustrates the equatorial temperature distribution up to $1 \mathrm{hPa}$. Temperatures decrease slightly where water vapor in Fig. 4 decreases, and the largest temperature increases near the tropopause in Fig. $6 \mathrm{~b}$ are coincident with the largest water vapor increases at this level (Fig. 4b). Thus it appears that temperature changes are affecting the annual cycle in water vapor in the simulations. There are still increases in stratospheric water vapor everywhere in the supersaturation simulation. Consistent with Fig. 6b, tropical cold point tropopause temperature in the supersaturation simulation warms by $1^{\circ} \mathrm{K}$ in boreal summer, with virtually no change in boreal winter. High latitude changes in temperature in the southern polar stratosphere are also largest in September-November (not shown).

Thus, the amplitude of the annual cycle of temperature around the tropical tropopause increases in the supersaturation case, with larger temperature changes in July-October than in December-March. This appears to be due to larger changes (reductions) in tropical high clouds in boreal summer, with the result that there is an extra $5-15 \mathrm{Wm}^{-2}$ of outgoing longwave radiation in this season, which is consistent with warmer temperatures above the cloud region in the lower stratosphere. The seasonal changes may be due 

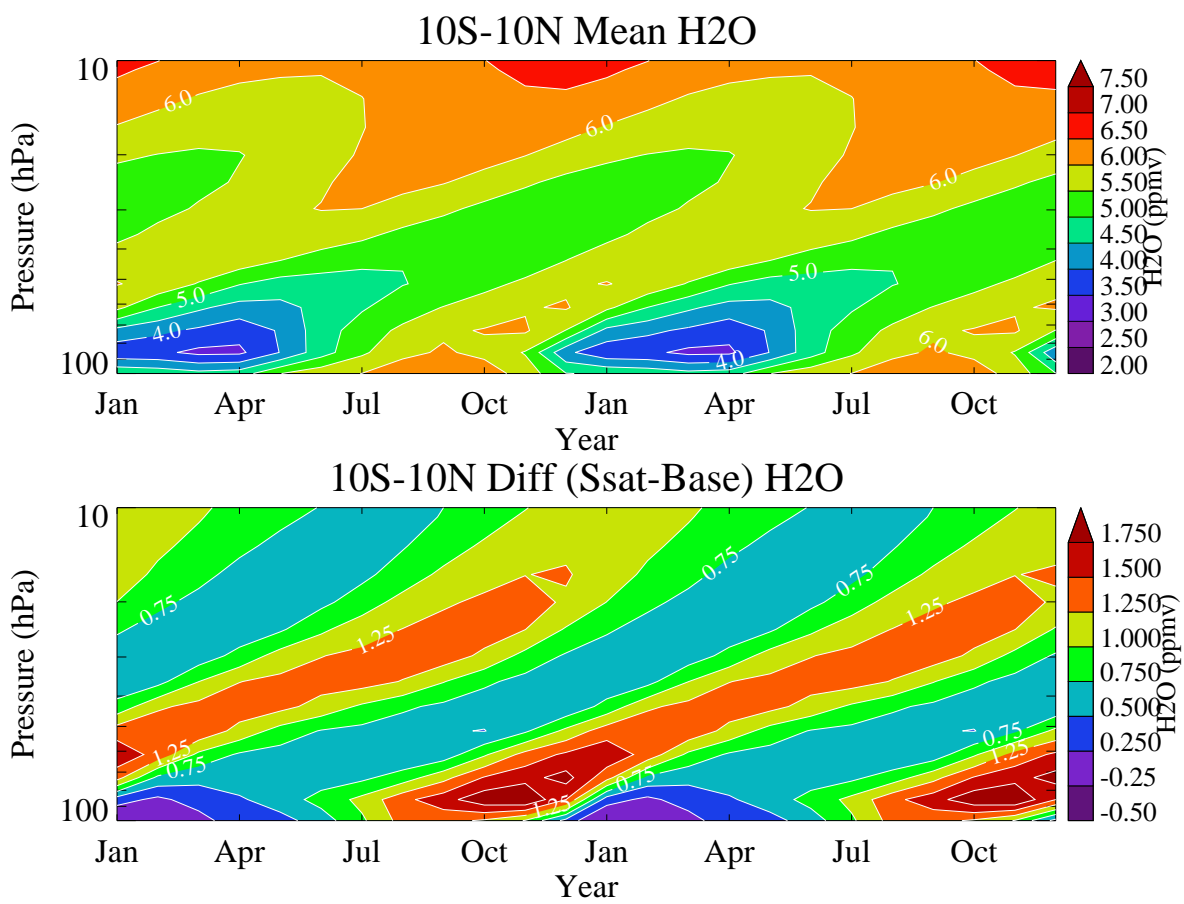

Fig. 4. Zonal mean tropical (10 S-10 N) monthly water vapor on the equator for (A) Base case (Top) and (B) difference between supersaturation and base cases (SSAT - Base) in ppmv (bottom). Mean annual cycle is repeated twice.

to different averaged humidities. June-August upper tropospheric relative humidities and cloud cover (which is a function of RH) are higher than in December-February. In addition, seasonal changes to the residual circulation in the stratosphere may also play a role (see below).

\subsection{Circulation and Long Lived Trace Species}

Given the decreases in temperature seen at high latitudes in Fig. 5 and the increases in temperature in the tropics, it is obvious to ask if circulation changes might account for this difference. A decrease in the equatorial upwelling and corresponding decrease in high latitude descent would alter temperatures in a similar manner to Fig. 5, increasing temperatures in the tropics (reduced adiabatic cooling) and decreasing them at high latitudes (decreased adiabatic warming). To better understand the stratospheric circulation, we have calculated the Transformed Eulerian Mean (TEM) circulation (Andrews et al., 1987) for both runs. TEM velocities are calculated following Andrews et al. (1987), Eq. (3.5.1). The annual residual mean vertical motion $\left(\bar{w}^{*}\right)$ for the base case is plotted in Fig. 7a, and features upward motion in the tropics and downward motion at the poles.

Figure $7 \mathrm{~b}$ illustrates the difference between the supersaturation and base simulations. Relative to the base case, the magnitude of down-welling at high latitudes of the Southern Hemisphere in the supersaturation run is $20 \%$ less. In Fig. $7 \mathrm{~b}$ this reduction is positive since down-welling is a negative

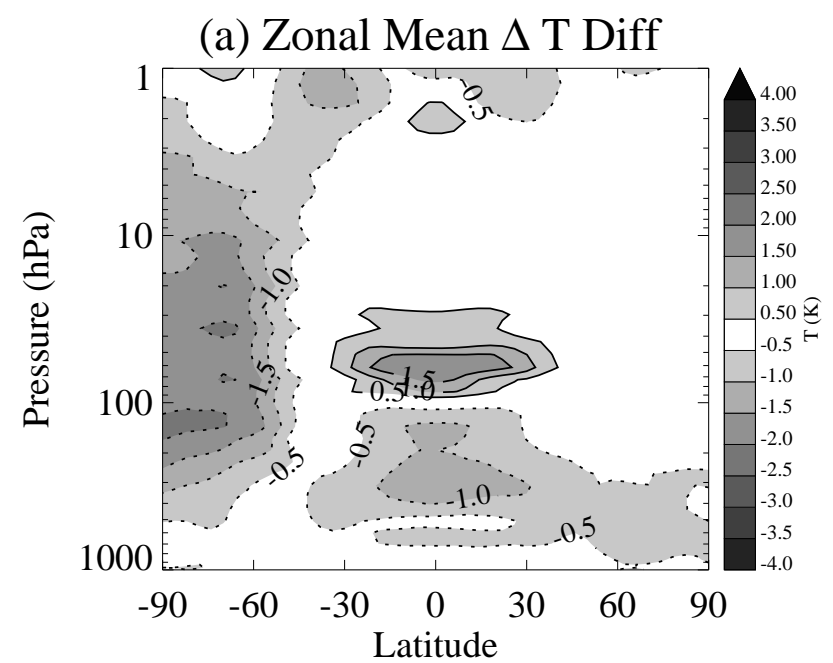

Fig. 5. Annual zonal mean differences (Supersaturation - Base) in Temperature in ${ }^{\circ} \mathrm{K}$.

vertical velocity. There are slightly larger changes at higher altitudes (lower pressures) near $1 \mathrm{hPa}$. This is near the region where temperatures are cooling (Fig. 5).

Figure 8 illustrates the annual cycle of the TEM meridional velocity, $\bar{v}^{*}$, in Fig. 8a, and the annual cycle of the TEM vertical velocity, $\bar{w}^{*}$, in Fig. $8 \mathrm{~b}$, at $61 \mathrm{hPa}$, near the 

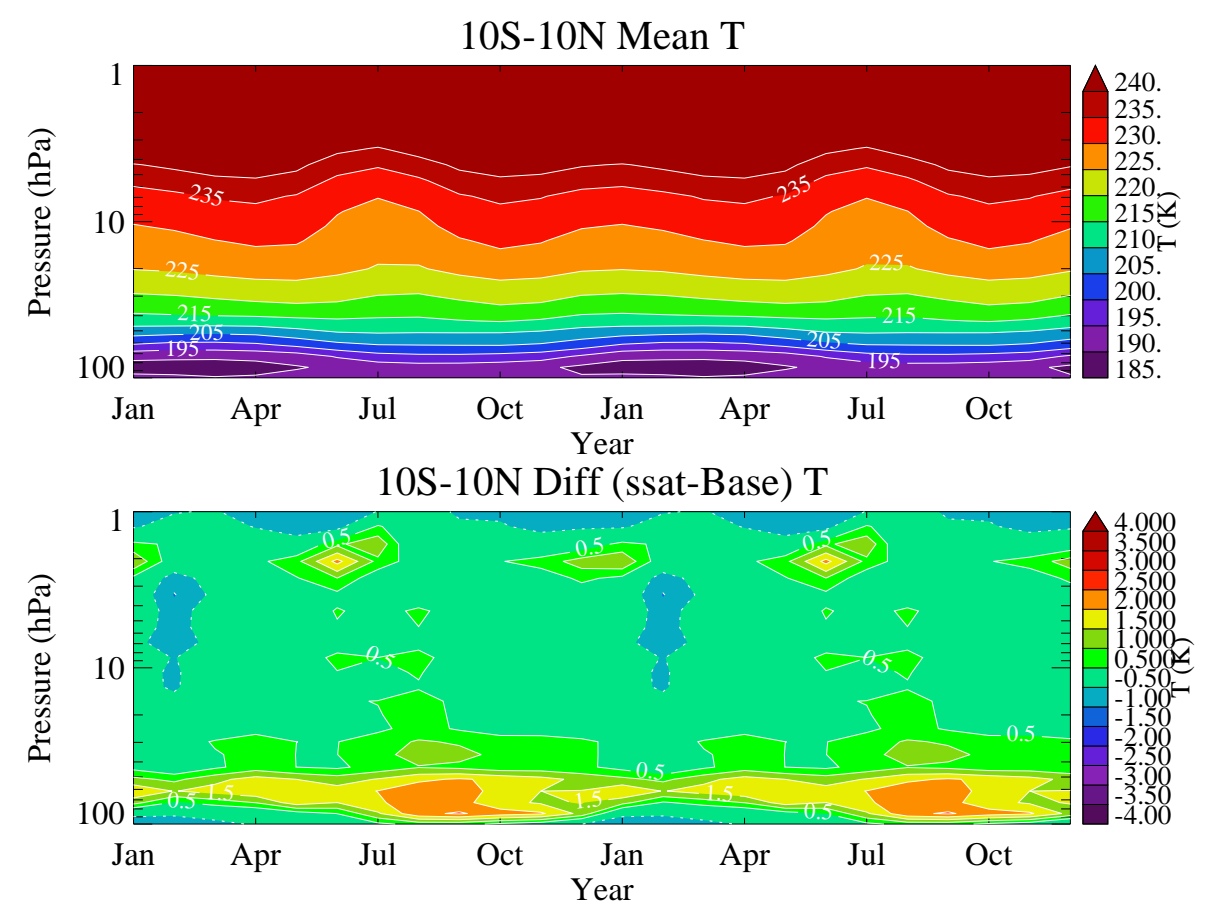

Fig. 6. Zonal mean tropical $(10 \mathrm{~S}-10 \mathrm{~N})$ monthly temperature (in $\left.{ }^{\circ} \mathrm{K}\right)$ on the equator for $(\mathbf{A})$ Base case (Top) and (B) difference between supersaturation and base cases (SSAT - Base) (bottom). Mean annual cycle is repeated twice.
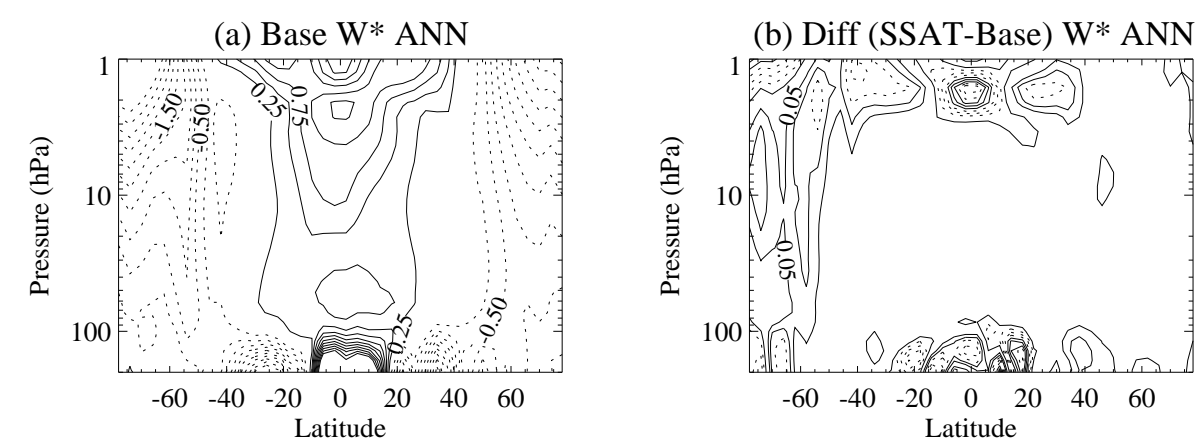

Fig. 7. Annual mean residual vertical velocity $\left(\bar{w}^{*}\right)$ in $\mathrm{cm} / \mathrm{s}(\mathbf{A})$ base case. Contour interval $0.25 \mathrm{~cm} / \mathrm{s}$. (B) Difference between supersaturation and base case (SSAT - Base). Contour interval $\pm 0.05 \mathrm{~cm} / \mathrm{s}$.

maximum difference in tropical temperatures. In the tropics from May to September there are decreases in tropical upwelling (Fig. 8b), which are consistent with the temperature changes in Fig. 5. In addition, there are decreases in downward vertical velocity at high southern latitudes in Fig. 8b. These changes are also consistent with changes to the vertical velocity. The horizontal velocity (Fig. 8a), shows a decrease in southward meridional flow in the supersaturation case throughout most of the year, and especially from JulyOctober. These differences are associated with an increase in the speed of the Southern Hemisphere polar jet in the simulations.
Another way of checking for consistency of the vertical motion changes is to examine long lived tracers. Figure 9 plots the percent change in concentration (mixing ratio) of $\mathrm{CH}_{4}$ (Fig. 9a) and the temporal change in the Age of Air (Fig. 9b). Methane has a tropospheric source and decay in the stratosphere. Figure 9a indicates decreases at southern polar latitudes, consistent with a slowing of the stratospheric circulation and more time for chemical destruction. It does not appear as if there are changes in $\mathrm{HO}_{\mathrm{x}}$ to cause chemical changes in methane (see discussion of chemistry below).

A similar picture is also seen by calculating the Age of Air (Waugh and Hall, 2002) in the stratosphere from the 
(a) $\mathrm{V}^{*} 24 \mathrm{mb}$ Ssat-Base $(\%)$

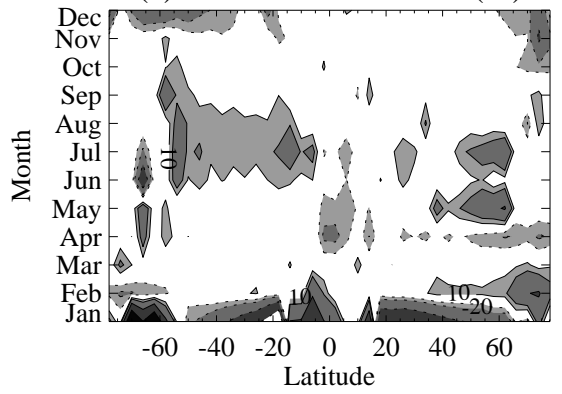

(b) $\mathrm{W}^{*} 24 \mathrm{mb}$ Ssat-Base (\%)

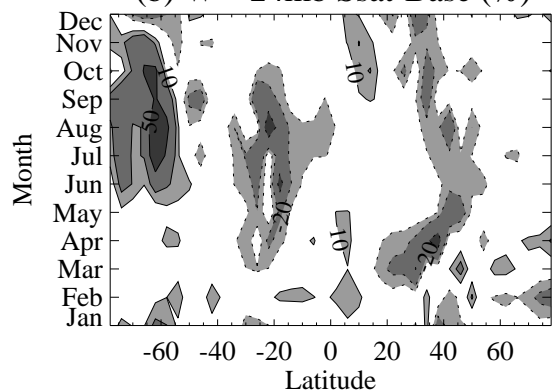

Fig. 8. Annual cycle of monthly mean differences (SSAT - Base)/Base in percent for (A) TEM meridional residual velocity $\left(\bar{v}^{*}\right)$ and (B) TEM vertical residual velocity $\left(\bar{w}^{*}\right)$. Contour interval $\pm 10,20$ and $50 \%$.

(a) Zonal Mean $\Delta \mathrm{CH} 4 \operatorname{Diff}(\%)$

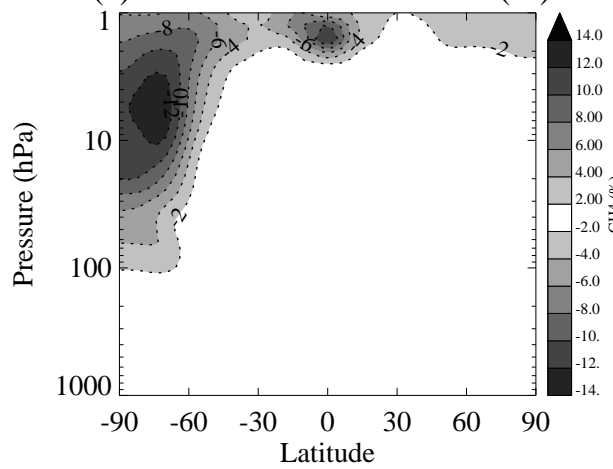

(b) Zonal Mean $\Delta$ AOA1 Diff

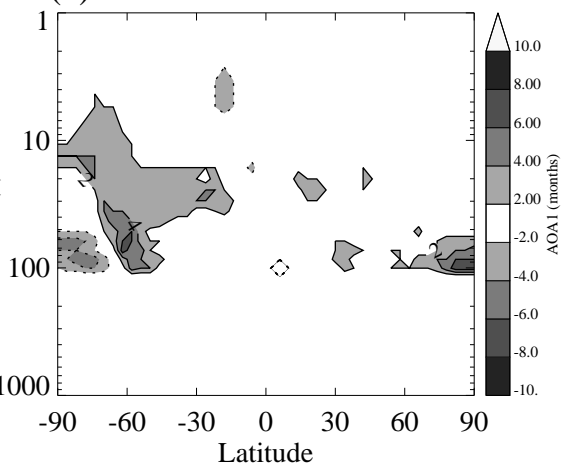

Fig. 9. Annual zonal mean differences in $(\mathbf{A}) \mathrm{CH}_{4}$ mixing ratio in percent (SSAT - Base)/Base and (B) Difference in Age of Air (AOA) in Months (SSAT - Base).

simulations (Fig. 9b). Southern polar latitudes have an older age in the supersaturation simulation by 2-6 months (with a mean age of 4-4.5 years). This is consistent with the circulation and chemistry changes, indicating a slowing of the stratospheric circulation, with a change occurring mostly in Southern Hemisphere winter.

The simulations have also been examined for significant changes to the tropospheric circulation. In general there appear to be small changes in the Northern Hemisphere tropospheric circulation. The increase in the Southern Hemisphere stratospheric polar jet appears to extend all the way to the surface (but changes are only of the order of $1-3 \mathrm{~ms}^{-1}$ ). There is virtually no change in the $200 \mathrm{hPa}$ streamfunction.

\subsection{Ozone and other species}

The changes in temperature (Fig. 5) and water vapor (Fig. 3) due to allowing supersaturation will also likely have impacts on chemistry in the UT/LS region and throughout the stratosphere. One of the benefits of using WACCM3 is that changes to chemical species as a result of the changes to physics can be assessed in a consistent, coupled framework.
However, in a coupled chemistry-climate model, discerning root causes in the coupled system is difficult (as will be shown below).

Figure 10 plots the annual zonal mean percent difference in ozone between the two simulations. $\mathrm{O}_{3}$ increases in the tropical lower stratosphere by $5-10 \%$ in the supersaturation simulation. It decreases slightly in the middle troposphere, as well as decreasing by up to $18 \%$ in the Southern Hemisphere lowermost stratosphere.

The seasonal cycle of tropical ozone changes is illustrated in Fig. 11. The changes (in ppbv) in Fig. 11a need to be taken in the context of ozone concentrations, so that the middle stratospheric changes of $\pm 200 \mathrm{ppbv}$ are in percentage terms (Fig. 11b) smaller than the $50 \mathrm{ppbv}$ change in the lower stratosphere. In the lower stratosphere, the ozone increase maximizes in July to October, and is consistent with the seasonal cycle of temperature (Fig. 6) and water vapor (Fig. 4) changes. This change in ozone is also consistent with slowing of the stratospheric circulation, which would allow more time for ozone production in the tropical lower stratosphere. In the middle and upper stratosphere there is a "dipole" of 


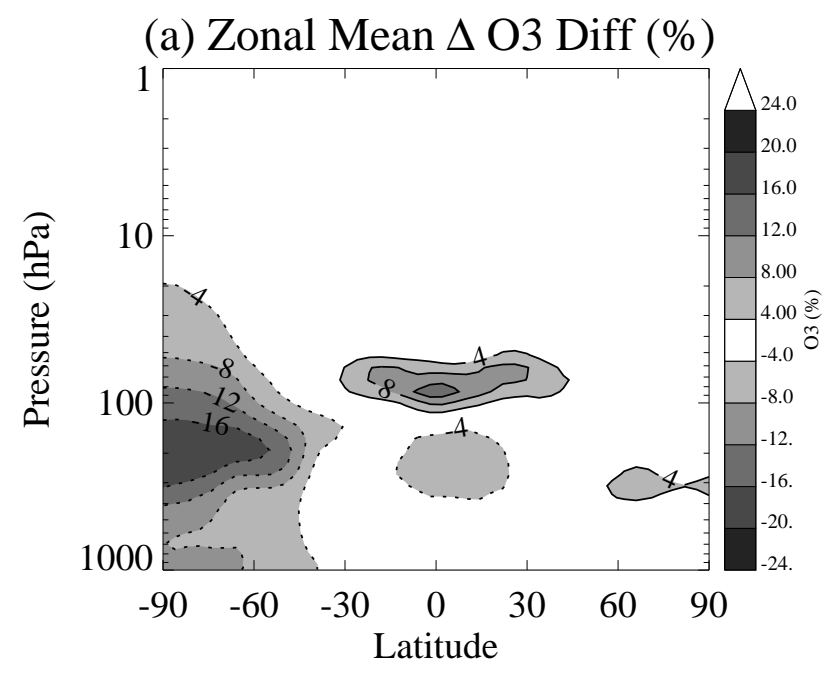

Fig. 10. Annual zonal mean percent differences (SSAT Base)/Base in Ozone mixing ratio.

decreases and then increases (Fig. 11a) which are generally less than $\pm 4 \%$ of the ozone concentration in Fig. 11b). Note that the "dipole" is also consistent with decreased ozone in the middle stratosphere leading to increased UV penetration and increased ozone at lower levels (a "self-healing" effect). There are several other changes to the chemical balance of the UT/LS region, which occur in the supersaturation simulation and will help with interpreting the changes to ozone. These are discussed briefly below.

Increases in $\mathrm{HO}_{\mathrm{x}}$ are expected due to the changes in water vapor in the region. $\mathrm{HO}_{\mathrm{x}}$ increases in the supersaturation simulation by $15-20 \%$ in the lower tropical stratosphere, located in the same region as the ozone (Fig. 10), temperature (Fig. 5) and water vapor (Fig. 3) increases. Total reactive nitrogen $\left(\mathrm{NO}_{\mathrm{y}}\right)$ and the more active odd nitrogen molecules $\left(\mathrm{NO}_{\mathrm{x}}=\mathrm{NO}+\mathrm{NO}_{2}\right)$ also change in the supersaturation case. The increased $\mathrm{HO}_{\mathrm{x}}$ converts more $\mathrm{NO}_{\mathrm{x}}$ to $\mathrm{HNO}_{3}$, decreasing the $\mathrm{NO}_{\mathrm{x}} / \mathrm{NO}_{\mathrm{y}}$ ratio between $5-10 \%$ (depending on altitude). This has the impact of reducing the odd-oxygen loss importance of $\mathrm{NO}_{\mathrm{y}}$. The opposite is true for the total reactive chlorine $\left(\mathrm{Cl}_{\mathrm{y}}\right)$ family. Here, increases in $\mathrm{HO}_{\mathrm{x}}$ convert more $\mathrm{HCl}$ to $\mathrm{ClO}$, and increasing the $\mathrm{ClO} / \mathrm{HCl}$ ratio by $5-$ $20 \%$ (depending on altitude), increasing the odd-oxygen loss importance of the $\mathrm{Cl}_{\mathrm{y}}$ family. This chemical sensitivity of increased $\mathrm{HO}_{\mathrm{x}}$ repartitioning reservoir species to active forms in the $\mathrm{NO}_{\mathrm{y}}$ and $\mathrm{Cl}_{\mathrm{y}}$ families is consistent with the discussion in Dvortsov and Solomon (2001).

In line with previous work (Stenke and Grewe, 2005), we see a very small impact of increased $\mathrm{H}_{2} \mathrm{O}$ on ozone chemistry in the stratosphere, with impacts of just a few percent above the lower stratosphere. However, it should be pointed out that for a similar (+1 ppmv) perturbation, Stenke and Grewe (2005) reported slight decreases in ozone in the lower-to-mid stratosphere. We see both decreases and increases depending on altitude, latitude, and season. In the UT/LS region, our model is in a situation where there is net ozone production with increased $\mathrm{HO}_{\mathrm{x}}$, leading to a slight increase in ozone in this region (Figs. 10 and 11). An analysis of production and loss rates indicates that the increase in ozone in the UTLS region is likely due to enhanced ozone production through the $\mathrm{HO}_{\mathrm{x}}-\mathrm{NO}_{\mathrm{x}}$ "smog" reactions, and decreases odd oxygen loss through reductions to the $\mathrm{NO}_{\mathrm{x}} / \mathrm{NO}_{\mathrm{y}}$ ratio. Such a situation is also described by Dvortsov and Solomon (2001). This region of ozone production in the UTLS was not seen by Stenke and Grewe (2005). We have compared our ozone loss rates at mid-latitudes where data is available, and find that our odd-oxygen loss processes appear to be adequately represented, i.e., the $\mathrm{HO}_{\mathrm{x}}$ and $\mathrm{NO}_{\mathrm{x}}$ crossover point is consistent with balloon observations (Osterman et al., 1997). This increases our confidence in our results.

Figure 12 plots the difference in total column ozone between the simulations. Here we see only very small changes in ozone (less than $\pm 3 \%$ ) outside of the Southern Hemisphere high latitudes. In the polar Southern Hemisphere region, ozone decreases are consistent with changes in the temperature and circulation noted above. In this region, temperature decreases (Fig. 5), which increases the heterogeneous conversion on sulfate aerosols of reservoir species (e.g., $\mathrm{HCl}$ and $\left.\mathrm{ClONO}_{2}\right)$ to more active forms $(\mathrm{ClO})$, and increasing odd-oxygen (ozone) loss. The polar Southern Hemisphere odd-oxygen loss is strongest in austral spring, where it affects column ozone by $10-15 \%$ (Fig. 12).

In summary, the changes in ozone are modest, and not significant outside of polar regions. Small ozone increases in the lower stratosphere appear to be due to increases in ozone production via $\mathrm{HO}_{\mathrm{x}}-\mathrm{NO}_{\mathrm{x}}$ reactions. Above this region, decreases in ozone are consistent with the direct effect of increased catalytic ozone loss from increased $\mathrm{HO}_{\mathrm{x}}$ and the effect that increased $\mathrm{HO}_{\mathrm{x}}$ has on repartitioning odd-oxygen loss in the $\mathrm{NO}_{\mathrm{y}}$ and $\mathrm{Cl}_{\mathrm{y}}$ families. The change in ozone in the lower stratosphere is also consistent with the slowing of the mean circulation and with a "self healing" effect of decreasing ozone at upper levels increasing it below.

\subsection{Radiation}

Changes to the radiation balance of the simulation are expected from the changes to clouds, water vapor and ozone, which together dominate the radiation balance of the UT/LS region, particularly in the Tropical Tropopause Layer (Gettelman et al., 2004). Changes to average tropical heating rates between the two simulations are shown in Fig. 13. These are all sky values (including the effects of clouds). Most of the differences in heating rates between the two simulations occur in the middle and upper troposphere. The supersaturation case has slightly lower net heating from the level of zero heating (about $200 \mathrm{hPa}$ ) up to $70 \mathrm{hPa}$, and significantly more cooling in the middle troposphere. Note that 

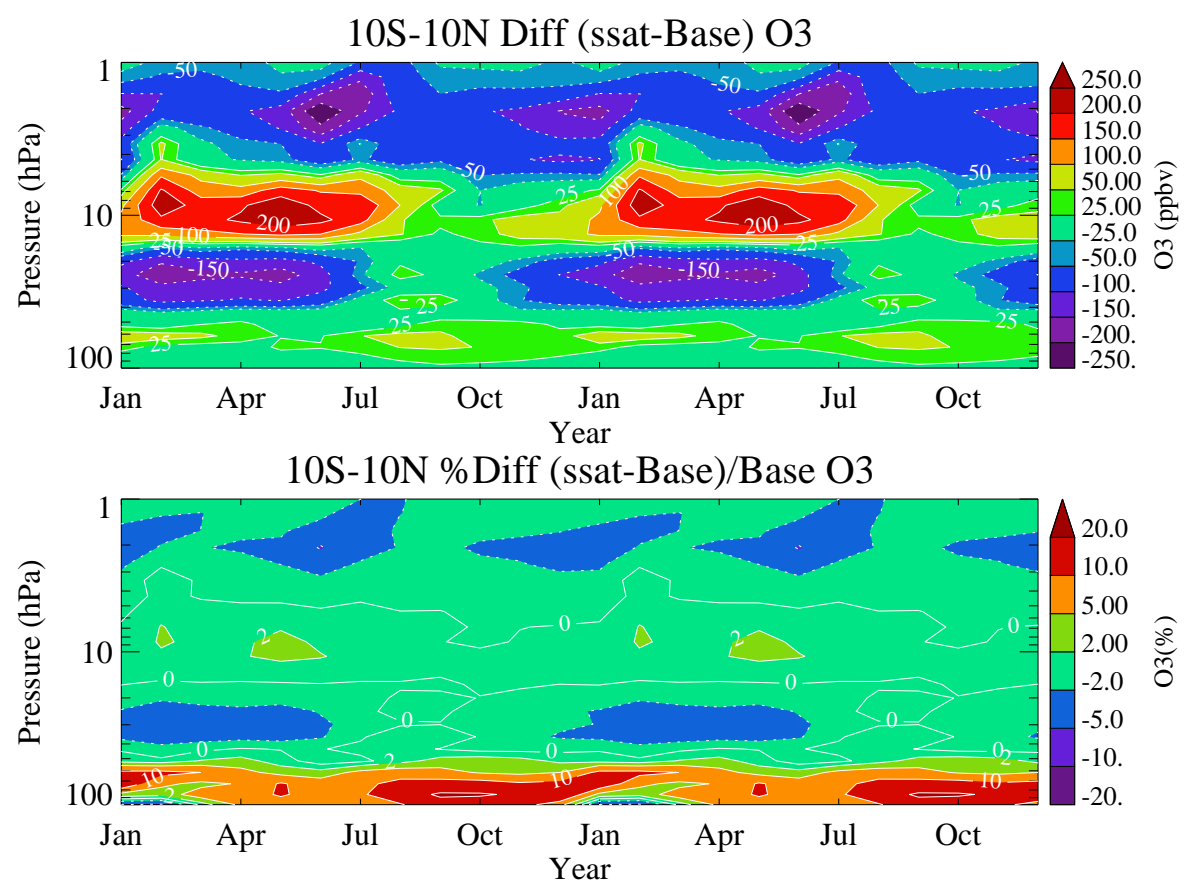

Fig. 11. Zonal mean tropical (10 S-10N) monthly ozone difference between supersaturation and base cases. (A) Top: difference (in ppbv) and (B) bottom: percent difference (SSAT - Base)/Base. Mean annual cycle is repeated twice. Contour levels in top panel are not regular.

cooling occurs because of more water vapor. This result likely means that there is a complex interplay of the changes to the overlying cloud as well as the direct radiative effects of water vapor. It is also likely that the reduction of cloud cover enhances the clear sky cooling from water vapor throughout this region.

In order to investigate the causes of the heating rate differences, we have taken average profiles of temperature, water vapor and cloud liquid water path and input these to an offline version of the radiative transfer code (a column radiation model). Analysis of these runs indicates that ozone is a negligible contributor to the differences except in the lower stratosphere where the ozone changes modify heating rates by 10 $20 \%$. Given long (20-30 day) radiative relaxtation times near the tropical cold point $(80-90 \mathrm{hPa})$, these ozone increases might play a role in warming the region. Multiple single column simulations at different latitudes were integrated to estimate the global radiation balance. This analysis yields a global difference in the top of model flux of $+0.8 \mathrm{Wm}^{-2}$, which is basically the same as the difference in globally averaged residual radiation. The increased absorption due to water vapor in the stratosphere combines with the reduction in cloudiness which allows water to enter the stratosphere. The moderate impact on lower stratospheric temperatures appears to be due to the radiative effect of clouds, and possible dynamical effects on the residual circulation. We do not see evidence for strong feedbacks of water vapor on tropopause temperatures, particularly the minimum temperatures.

\section{Discussion and conclusions}

\subsection{Discussion}

Overall, the addition of supersaturation to the WACCM3 coupled chemistry climate model has expected impacts on the simulation of UT/LS humidity and modest further effects on the simulation. In general the model humidity is responding as expected to the imposed changes.

The largest humidity effects are decreases in high cloudiness and increases in water vapor in the stratosphere. The increase in $\mathrm{H}_{2} \mathrm{O}$ is of similar magnitude to the imposed changes to the condensation closure ( $\sim 20 \%$ increase in water vapor). The increase occurs throughout the tropics, and is largest in regions with most cirrus cloudiness (coincident with regions of deep convection in the tropics).

There are also reductions in the thickest high clouds (thick cirrus and anvil clouds). There are small shifts in tropical precipitation from the Indian to the Pacific Ocean. These changes will have an impact on the tropospheric hydrologic cycle, and are coupled to radiative effects to slightly change tropospheric transport.

In addition to these changes, there appears to be a seasonally varying change in temperature in the tropical tropopause region. This also affects water vapor entering the stratosphere. The largest effects are seen during the "cooling phase" of the annual cycle of tropical tropopause temperatures from August-November. Temperatures during this 


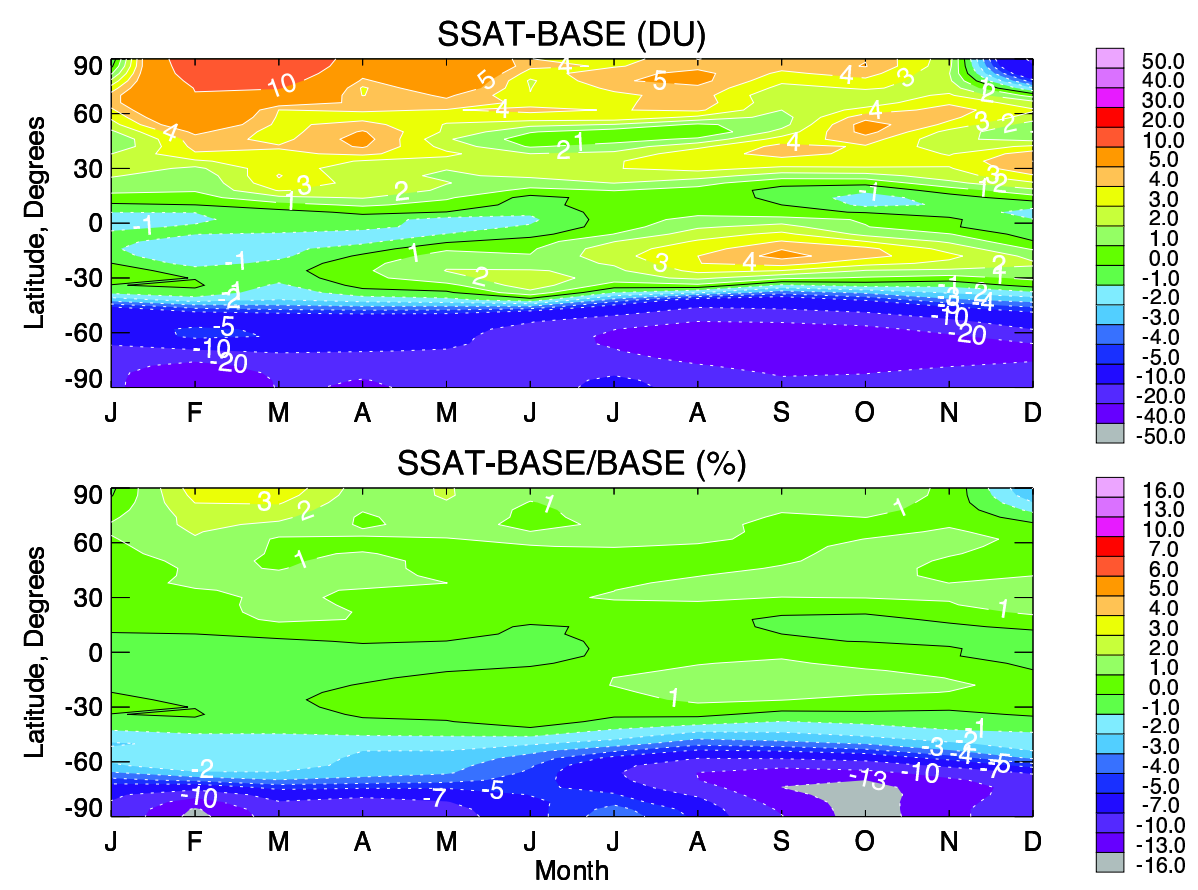

Fig. 12. Zonal mean Column ozone monthly difference between supersaturation and base cases. (A) Top: difference (in DU) and (B) bottom: percent difference (SSAT - Base)/Base.

period are warmer, again throughout much of the tropopause region. It appears as if the cooling is delayed by a month or so in this period, though the final minimum temperatures in January-March at the tropical cold point are similar. The base case simulation has a smaller annual cycle of tropopause temperatures than observed. Adding supersaturation yields a more realistic annual cycle. The seasonal change in cloudiness is likely a result of higher humidities and base cloud cover during boreal summer, thus it is more sensitive than during boreal winter.

The change in temperature is likely due several consistent factors. Reductions in clouds increase radiative heating, changes to water vapor change ozone which may also heat and the heating may affect wave propagation which modifies the circulation in the stratosphere, coupling these changes to higher latitudes.

Part of the temperature change appears due to the radiative impacts of reduced high clouds. The shortwave effect appears to dominate over the long wave effect (perhaps counter intuitively). The magnitude of the radiative change $\left(+0.8 \mathrm{Wm}^{-2}\right)$ is due to the effects of clouds $\left(+0.6 \mathrm{Wm}^{-2}\right)$ and the increase in water vapor $\left(+0.2 \mathrm{Wm}^{-2}\right)$.

The chemical impact of the changes is modest in the tropics and more significant at high latitudes. We see very little impact on tropical column ozone. But a detailed analysis of the tropical heating rates indicates that near the cold point the ozone changes (due to chemistry) might be contributing to increased temperatures. Seasonally, the ozone changes at
$90 \mathrm{hPa}$ or so occur from August-November (Fig. 11b), which is similar to the seasonality of temperature changes at this level (Fig. 6b).

The changes in temperature and meridonal temperature gradients affect wind patterns, in particular the S. Hemisphere polar jet. The change in winds may be driving changes to the stratospheric Brewer-Dobson circulation which couples tropical changes to higher latitudes. Based on an analysis of residual velocities, long lived tracers and Age of Air estimates, the circulation appears to slow in Southern Hemisphere Fall-Winter (August-November). This creates temperature anomalies in the $\mathrm{S}$. Hemisphere polar regions.

There are small increases in ozone in the lower stratosphere, which appear to be due to increased production via $\mathrm{HO}_{\mathrm{x}}-\mathrm{NO}_{\mathrm{x}}$ "smog" reactions. The changes are also consistent with a slowing of the circulation.

In high latitudes, the changes to the tropical temperatures and resultant change in the circulation significantly affect Southern Hemisphere polar ozone. Decreases in temperature in August-November increase ozone loss reactions, resulting in column decreases of $10-15 \%$.

Since the amplitude of the annual cycle of tropical tropopause temperatures is too small in the base case, and summertime water vapor slightly low, the changes with supersaturation represent an improvement to the mean model climate. These changes ultimately are forced by changes to tropical cloudiness as noted above. 


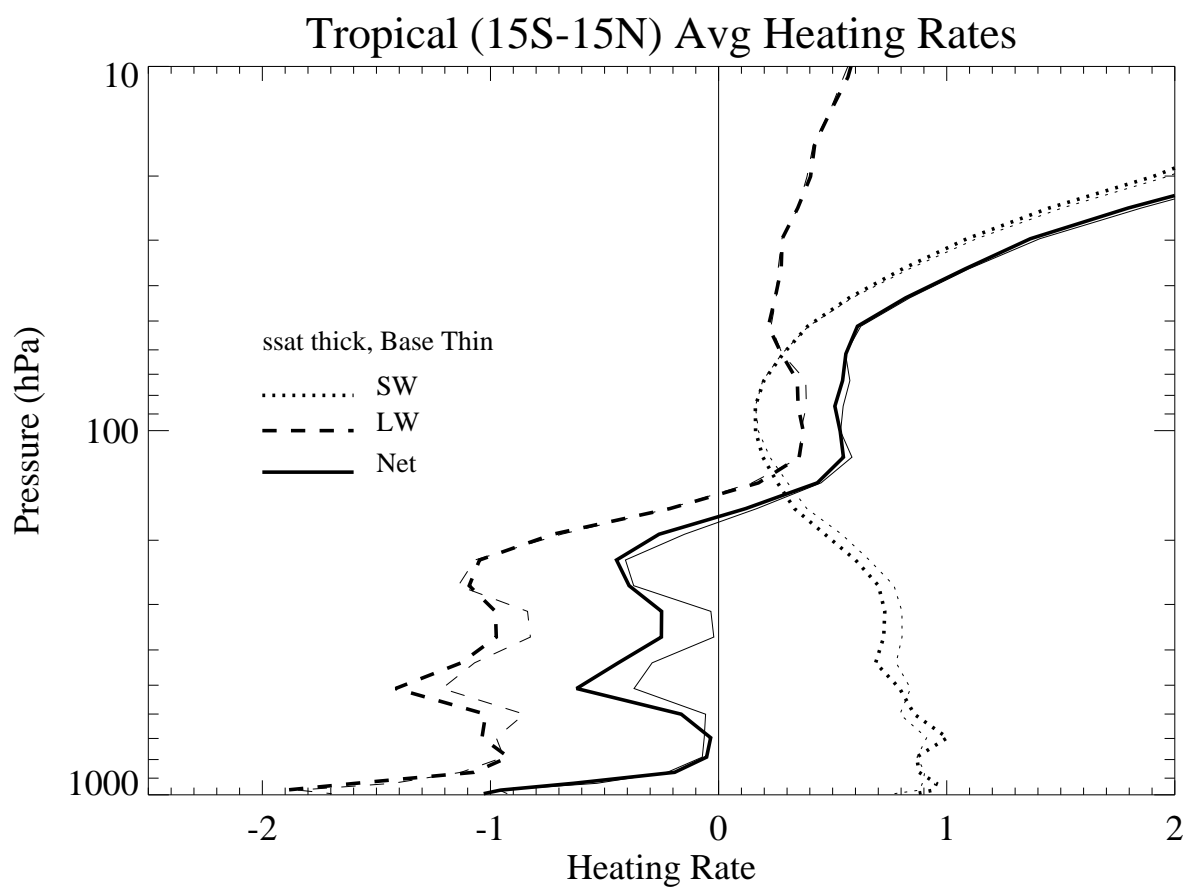

Fig. 13. Mean tropical $\left(15 \mathrm{~S}-15 \mathrm{~N}\right.$ ) average heating rates (in $\mathrm{K} \mathrm{day}^{-1}$ ) for the Base case (thin) and Supersaturated case (thick). Net radiation solid, longwave dashed, shortwave dotted.

Since the simulations use fixed surface temperatures, these simulations are not designed to examine effects of stratospheric water vapor on surface temperatures. We also do not see evidence of a strong "stratospheric water vapor feedback" (Stuber et al., 2001) in the simulations from changing stratospheric water vapor by $10-20 \%$. The UT/LS region may be more sensitive to radiative forcing, but the coupled chemistry and physics limit the impact. In this work, with an internally consistent method for a modest change in water vapor, we note a top of atmosphere change in the radiative balance of $+0.8 \mathrm{Wm}^{-2}$. This is not the direct effect of the increase in stratospheric water vapor, because it also includes the effect of significant modifications to clouds, and the reduction in net cloud forcing (which is negative, so the change is positive) of $+0.6 \mathrm{Wm}^{-2}$, which contributes the largest share to the change in radiative balance in the model. The residual of about $+0.2 \mathrm{Wm}^{-2}$ is similar to that found by Forster and Shine (2002) for a similar change in stratospheric water vapor. Thus in these simulations clouds are the dominant response, but stratospheric water vapor appears to respond as found in previous work. In general, if changes to stratospheric water vapor were coupled to significant changes in cloudiness in the tropopause region, the cloud radiative effects would likely swamp any direct radiative impact of stratospheric water vapor.

\subsection{Implications for global models}

This study has several important implications for global model treatments of the UT/LS region. First is that stratospheric water vapor responds directly to temperature changes in WACCM3. Thus getting appropriate temperature variability on seasonal to annual and inter-annual timescales is important for the future chemistry and dynamics of the stratosphere. It is however difficult to know what the expected trend in tropical tropopause temperatures is. We know that changes to water vapor in the stratosphere are expected from oxidation of methane (SPARC, 2000) and that these changes are not monotonic trends (Randel et al., 2004).

It is clear from the simulations that stratospheric water vapor responds to temperatures. It is also clear that changes to the threshold for condensation can have significant impacts on clouds. The radiative effects of these clouds can have significant effects on the coupled chemistry and climate of the stratosphere. In these simulations, enhanced upwelling radiation and possibly increased water vapor, may be affecting tropical lower stratospheric temperatures. Warmer temperatures might also be dynamically forced, by changes in waves which force the overturning circulation. The reduced overturning Brewer-Dobson circulation appears to lower Southern Hemisphere polar temperatures and enhance polar ozone loss. This implies that changes to the distribution of aerosols that are ice nuclei which modify supersaturation may be important for affecting tropical clouds, stratospheric water 
vapor and even polar ozone. However, this result is likely to be dependent on the WACCM model biases, seasonality of effects on clouds and particularly an existing cold pole bias. Actual impacts on polar ozone are likely more modest.

The weakening of the stratospheric circulation found in these simulations runs counter to the strengthening of the circulation found for many of the models (including WACCM) forced with greenhouse gases by Butchart et al. (2007). The strengthening circulation found by Butchart et al. (2007) shows a clear increase in tropical upwelling, while the response here is mostly at high latitudes (Fig. 7b). It is not clear that the forcing between the simulations in Butchart et al. (2007) and in this study is compatible. The difference highlights potential uncertainties in predicting the state of the stratospheric circulation if the response to increasing stratospheric water vapor is very different from the response to increasing greenhouse gases.

Finally, we restate that this is a very crude way to implement supersaturation, but one that is consistent with the model physics. This study was intended as a scoping exercise, where we impose a change consistent with the model framework and investigate the impact of the change on the coupled system. In general, the supersaturation case has a better representation of water vapor in the stratosphere due to improvements in the annual cycle of tropical tropopause temperatures. The stratosphere is slightly moister than observed in this case, but this is a consequence of the gravity wave balance which affects tropical tropopause temperatures and is typically adjusted to match the mean observed temperature. However, changes to the circulation appear to cause excessive ozone loss and an enhanced cold pole problem in the Southern Hemisphere polar region.

Treatments for global models using these ideas for cold (ice) clouds exist (Kärcher et al., 2006). And better treatments for cloud closures in global models that allow bulk supersaturation have also been developed (Tompkins et al., 2007). This study highlights the importance of using these more realistic treatments for supersaturation in future global models.

Acknowledgements. Thanks to S. Walters for assistance with WACCM runs and acerbic encouragement. We also thank J. F. Lamarque, F. Sassi and W. J. Randel for comments. The National Center for Atmospheric Research is supported by the United States National Science Foundation.

Edited by: P. Haynes

\section{References}

Andrews, D., Holton, J., and Leovy, C.: Middle Atmosphere Dynamics, Academic Press, New York, 1987.

Boville, B. A., Rasch, P. J., Hack, J. J., and McCaa, J. R.: Represenation of Clouds and Precipitation in the Community Atmosphere Model Version 3 (CAM3), J. Climate, 19, 2184-2198, 2006.
Brasseur, G. P., Hauglustaine, D. A., Walters, S., Rasch, P. J., Muller, J.-F., Granier, C., and Tie, X. X.: MOZART, a global chemical transport model for ozone and related chemical tracers 1. Model description, J. Geophys. Res., 103, 28 265-28 289, 1998.

Butchart, N. A., Scaife, A., Bourqui, M., de Grandpré, J., Hare, S. H. E., Kettleborough, J., Langematz, U., Manzini, E., Sassi, F., Shibata, K., Shindell, D., and Sigmond, M.: Simulations of anthropogenic change in the strength of the BrewerDobson circulation, Clim. Dyn., 27, 727-741, doi:10.1007/s00382-006-0162-4, 2006.

Cess, R. D.: Water Vapor Feedback in Climate Models, Science, 310, 795-796, 2005.

Collins, W. D., Rasch, P. J., Boville, B. A., Hack, J. J., McCaa, J. R., Williamson, D. L., Briegleb, B. P., Bitz, C. M., Lin, S.-J., and Zhang, M.: The Formulation and Atmospheric Simulation of the Community Atmosphere Model: CAM3, J. Climate, 19, 2122-2161, 2006.

Dvortsov, V. L. and Solomon, S.: Response of the stratospheric temperatures and ozone to past and future increases in stratospheric humidity, J. Geophys. Res., 106, 7505-7514, 2001.

Eyring, V., Butchart, N., Waugh, D. W., et al.: Assessment of temperature, trace species, and ozone in chemistry-climate model simulations of the recent past, J. Geophys. Res., 111, D22308, doi:10.1029/2006JD007327, 2006.

Forster, P. M. d. F. and Shine, K. P.: Assessing the climate impact of trends in stratospheric water vapor, Geophys. Res. Lett., 29(6), 1086, doi:10.1029/2001GL013909, 2002.

Gettelman, A., Forster, P. M. de F., Fujiwara, M., Fu, Q., Vomel, H., Gohar, L. K., Johanson, C., and Ammerman, M.: Radiation balance of the tropical tropopause layer, J. Geophys. Res., 109, D07103, doi:10.1029/2003JD004190, 2004.

Gettelman, A., Fetzer, E. J., Eldering, A., and Irion, F. W.: The Global Distribution of Supersaturation in the Upper Troposphere from the Atmospheric Infrared Sounder, J. Climate, 19(23), 6089-6103, 2006.

Gierens, K. and Spichtinger, P.: On the size distribution of ice supersaturation regions in the upper troposphere and lower stratosphere, Ann. Geophys., 18, 499-504, 2000, http://www.ann-geophys.net/18/499/2000/.

Holton, J. R. and Gettelman, A.: Horizontal transport and dehydration in the stratosphere, Geophys. Res. Lett., 28, 2799-2802, 2001.

Holton, J. R., Haynes, P. H., Douglass, A. R., Rood, R. B., and Pfister, L.: Stratosphere-Troposphere Exchange, Rev. Geophys., 33, 403-439, 1995.

Horowitz, L. W., Walters, S., Mauzerall, D. L., et al.: A global simulation of tropospheric ozone and related tracers: Description and evaluation of MOZART, version 2, J. Geophys. Res., 108(D24), 4784, doi:10.1029/2002JD002853, 2003.

Jensen, E., Smith, J. B., Pfister, L., et al.: Ice Supersaturations exceeding $100 \%$ at the cold tropical tropopause: implications for cirrus formation and dehydration, Atmos. Chem. Phys., 5, 851862,2005 , http://www.atmos-chem-phys.net/5/851/2005/.

Jensen, E. J., Read, W. G., Mergenthaler, J., Sandor, B. J., Pfister, L., and Tabazadeh, A.: High humidities and subvisible cirrus near the tropical tropopause, Geophys. Res. Lett., 26, 23472350, 1999. 
Joshi, M., Shine, K., Ponater, M., Stuber, N., Sausen, R., and Li, L.: A comparison of climate response to different radiative forcings in three general circulation models: towards an improved metric of climate change, Clim. Dyn., 20, 843-854, doi: 10.1007/s00382-003-0305-9, 2003.

Kärcher, B. and Haag, W.: Factors controlling upper tropospheric relative humidity, Ann. Geophys., 22, 705-715, 2004, http://www.ann-geophys.net/22/705/2004/.

Kärcher, B. and Lohmann, U.: A parameterization of cirrus cloud formation: Homogenous freezing of supercooled aerosols, J. Geophys. Res., 107(D2), 4010, doi:10.1029/2001JD000470, 2002a.

Kärcher, B. and Lohmann, U.: A parameterization of cirrus cloud formation: Homogenous freezing including effects of aerosol size, J. Geophys. Res., 107(D23), 4698, doi:10.1029/ 2001JD001429, 2002b.

Kärcher, B., Hendricks, J., and Lohmann, U.: Physically based parameterization of cirrus cloud formation for use in atmospheric models, J. Geophys. Res., 111, D01205, doi:10.1029/ 2005JD006219, 2006.

Koop, T., Luo, B., Tsias, A., and Peter, T.: Water activity as the determinant for homogenous ice nucleation in aqueous solutions, Nature, 406, 611-614, 2000.

Mote, P. W., Rosenlof, K. H., McIntyre, M. E., et al.: An atmospheric tape recorder: The imprint of tropical tropopause temperatures on stratospheric water vapor, J. Geophys. Res., 101, 39894006, 1996.

Murphy, D. M. and Koop, T.: Review of the vapour pressure of ice and supercooled water for atmospheric applications, Quart. J. Roy. Meteorol. Soc., 131, 1539-1565, 2005.

Osterman, G. B., Salawitch, R. J., Sen, B., Toon, G. C., Stachnik, R. A., Pickett, H. M., Margitan, J. J., Blavier, J. F., and Peterson, D. B.: Baloon-borne measurements of stratospheric radicals and their precursors: Implications for the production and loss of ozone, Geophys. Res. Lett., 24, 1107-1110, 1997.

Ramanathan, V., Cess, R. D., Harrison, E. F., Minnis, P., Barkstrom, B. R., Ahmad, E., and Hartmann, D.: Cloud-Radiative Forcing and Climate: Results from the Earth Radiation Budget Experiment, Science, 243, 57-63, 1989.

Randel, W. J., Gettelman, A., Wu, F., Russell III, J. M., Zawodny, J., and Oltmans, S.: Seasonal variation of water vapor in the lower stratosphere observed in Halogen Occultation Experiment data, J. Geophys. Res., 106, 14 313-14 325, 2001.

Randel, W. J., Wu, F., Oltmans, S. J., Rosenlof, K., and Nedoluha, G. E.: Interannual changes of stratospheric water vapor and correllations with tropical tropopause temperatures, J. Atmos. Sci., 61, 2133-2148, 2004.
Rasch, P. J. and Kristjansson, J. E.: A Comparison of CCM3 Model climate using diagnosed and predicted condensate parameterizations, J. Climate, 11, 1587-1614, 1998.

Shindell, D. T.: Climate and ozone response to increased stratospheric water vapor, Geophys. Res. Lett., 28, 1551-1554, 2001.

Slingo, J. M.: The development and verification of a cloud prediction scheme for the ECMWF model, Quart. J. Roy. Meteorol. Soc., 113, 899-927, 1987.

SPARC: Assessment of Water Vapor in the Upper Troposphere and Lower Stratosphere, WMO/TD-1043, Stratospheric Processes and Their Role In Climate, World Meteorological Organization, Paris, 2000.

Spichtinger, P., Gierens, K., Leiterer, U., and Dier, H.: Ice supersaturation in the tropopause region over Lindenberg, Germany, Meteorologische Zeitschrift, 12, 143-156, 2003a.

Spichtinger, P., Gierens, K., and Read, W.: The global distribution of ice-supersaturated regions as seen by the Microwave Limb Sounder, Quart. J. Roy. Meteorol. Soc., 129, 3391-3410, 2003b.

Stenke, A. and Grewe, V.: Simulation of stratospheric water vapor trends: impact on stratospheric ozone chemistry, Atmos. Chem. Phys., 5, 1257-1272, 2005, http://www.atmos-chem-phys.net/5/1257/2005/.

Stuber, N., Ponater, M., and Sausen, R.: Is the climate sensitivity to ozone perturbations enhanced by stratospheric water vapor feedback?, Geophys. Res. Lett., 28, 2887-2890, 2001.

Stuber, N., Ponater, M., and Sausen, R.: Why radiative forcing might fail as a predictor of climate change, Clim. Dynamics, 24, 497-510, doi:10.1007/s00382-004-0497-7, 2005.

Tompkins, A. M., Gierens, K., and Rädel, G.: Ice supersaturation in the ECMWF forecast system, Quart. J. Roy. Meteorol. Soc., in press, 2007.

Waugh, D. W. and Hall, T. M.: Age of Stratospheric Air: Theory, Observations and Models, Rev. Geophys., 40(4), 1-26, 1010, doi:10.1029/2000RG000101, 2002.

Wennberg, P. O., Cohen, R. C., Stimpfle, R. M., Koplow, J. P., Anderson, J. G., Salawitch, R. J., Fahey, D. W., Woodbridge, E. L., Keim, E. R., Gao, R. S., Webster, C. R., May, R. D., Toohey, D. W., Avallone, L. M., Proffitt, M. H., Loewenstein, M., Podolske, J. R., Chan, K. R., and Wofsy, S. C.: Removal of Stratospheric $\mathrm{O}_{3}$ by Radicals: In Situ Measurements of $\mathrm{OH}$, $\mathrm{HO}_{2}, \mathrm{NO}, \mathrm{NO}_{2}, \mathrm{ClO}$ and BrO, Science, 266, 398-404, 1994. 